\title{
TOBACCO AND SMOKING
}

By Horace Joules, M.D., F.R.C.P. Central Middlesex Hospital

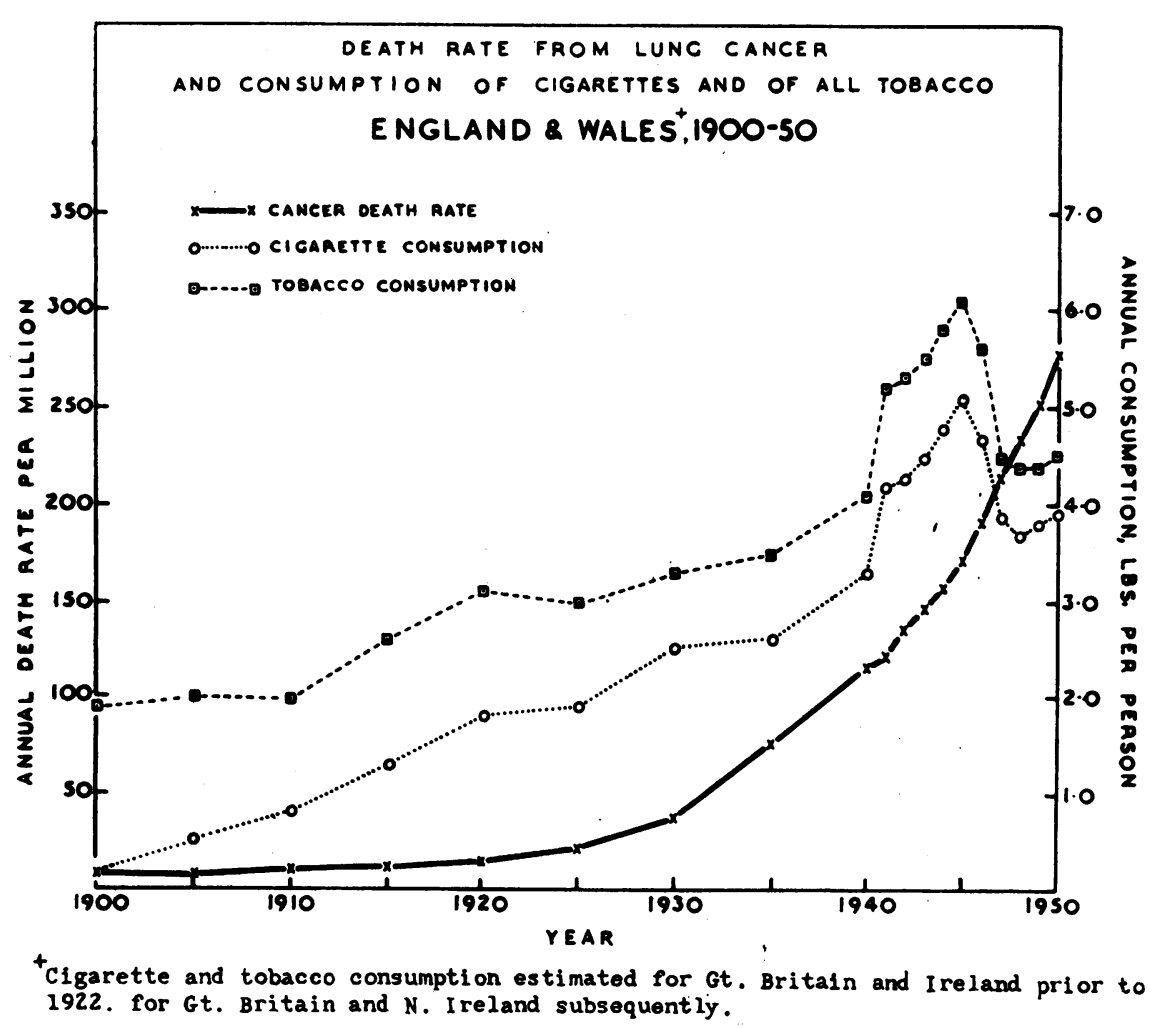

FIG. 1.-Consumption of tobacco and cigarettes from 1900-50 in England and Wales, plotted against annual death rate per million from cancer of the lung.

On each day of 1955 in Great Britain, 1 I,900,000 men aged 16 and over were smoking an average of 15.3 cigarettes. At the same time the average consumption of $6,300,000$ women smokers was 8.I daily.* The facts can either be regarded as a triumph for salesmanship or a measure of addiction in our community. Whatever our attitude it is essential that we attempt to assess objectively the effect that such indulgence is having on the health of our industrial nation.

Smoking has had its devotees in this country for almost 400 years, but until the beginning of this

\footnotetext{
*Figures obtained from the Hulton Readership Survey, to whom thanks are due.
}

century the amount smoked as cigarettes was very small, for pipe smoking was almost invariable. The mechanical difficulties associated with pipe smoking, although slight, limited the use of tobacco in many circumstances. The evolution of the cheap cigarette made access to smoking almost universal. It could be indulged in under almost any circumstances and at a moment's notice. .There is little doubt that the rigours of the 1914-18 war were responsible for a great spread of the habit. The stress of the appalling conditions on our troops in Flanders, and the strain of excessive hours on many factory workers demanded some relief. Cigarettes were offered and gratefully 


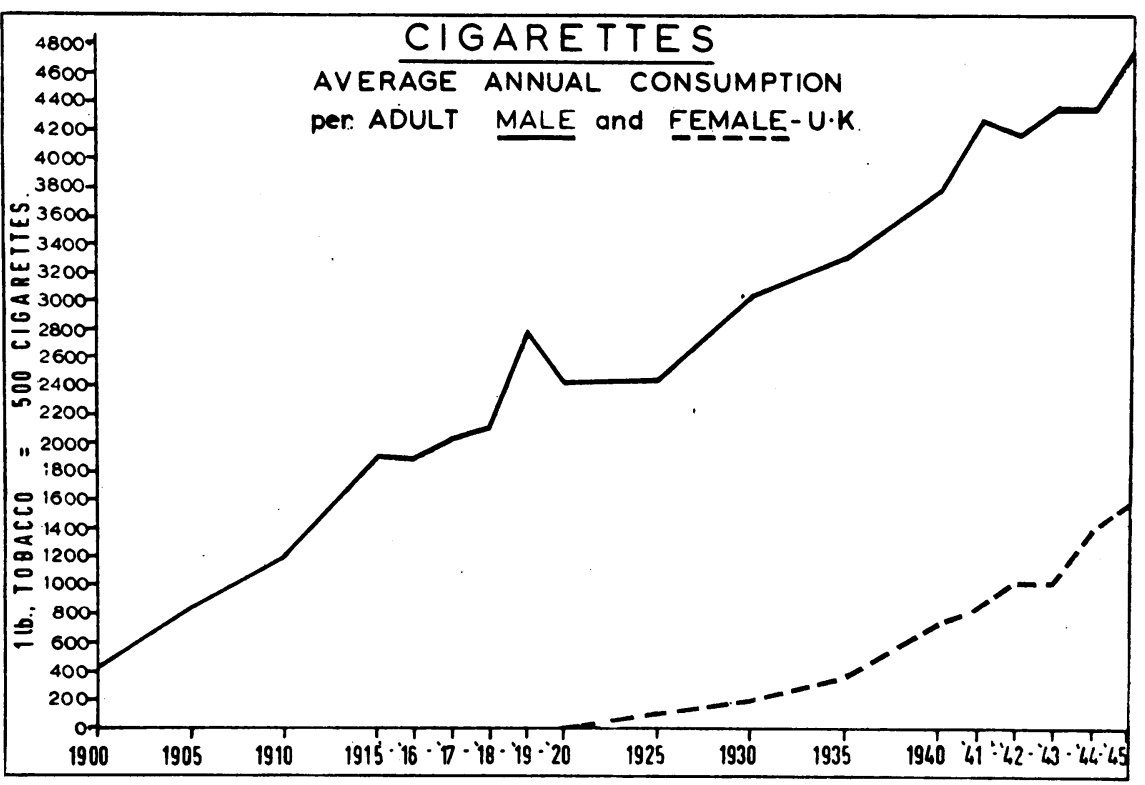

Fig. 2.- Annual number of cigarettes smoked, male and female aged 16 years and over, in Great Britain, $1900-45$.

accepted. Gradually we have been conditioned to the idea that mental strain is eased by nicotine and all pleasures are heightened by its aid. Many patients assure us that the habit is their only pleasure in life.

The growth in the use of tobacco in its various forms is illustrated in Fig. I-from this the transition to cigarettes during the past half century is very clear. However, it does not reveal the whole position for millions of cigarettes are made daily from tobacco purchased by the smoker. This process is said by those using it to ensure a less irritating smoke while the number of cigarettes made from each ounce of tobacco can vary with the state of the pocket. This increase of cigarette consumption for males and females is seen in Fig. 2.

All investigations into the effects of smoking suggest the pipe is less harmful and so many workers have concentrated on the chemistry and pharmacology of products of cigarette smoking. Mechanical devices of many types have been set up in imitation of human consumption but there is no general agreement on the conditions under which experimental smoking shall proceed. Consequently there is variation in the findings of the chemical composition of the smoke, while there is even greater variation in the tobacco used in different countries. The nicotine content of Burley and Turkish tobacco smoke is given as 4.93 and $1.99 \mathrm{mg}$. per cigarette, Bradford et al. (1937).
Our present knowledge of the chemistry is fully reviewed by Kosak (1955). The constituents are divided into aldehydes, ketones, acids, alcohol and phenols, alkaloids, other nitrogen compounds hydrocarbons and miscellaneous compounds organic and inorganic. The evidence of the presence of 67 of these seems to be valid, while 49 other substances reported are felt to be in need of further investigation. Intensive research continues in attempts to isolate the carcinogenic factors.

Of the alkaloids available nicotine is the only one present in an amount likely to give rise to assessable pharmacological actions. A standard Virginian cigarette may yield 2.5 to $3.0 \mathrm{mg}$. of nicotine, dependent upon the method of smoking. Those who smoke and inhale deeply will absorb 90 per cent. of this, while non-inhalers may metabolize less than ro per cent.

The action of nicotine on the human nervous system is extremely complex and very difficult to assess. The psychological factors are complicated and they may vitiate an evaluation of the pharmacological activity. Individual susceptibility is also a very important and unpredictable factor. The main effect on the nervous system is to stimulate, but larger doses may give rise to severe depression. The action on the vomiting centre, well known to those embarking on an early trial of the habit, is indirect and probably due to absorption from a swallowed solution. There is stimulation of the antidiuretic hormone of the posterior lobe of the 
pituitary as shown by Burn (195I). Nicotine is a neuro-muscular blocking agent and can in large doses cause death by neuro-muscular paralysis.

The effect on the circulation is again complex and it is doubtful if much of the experimental work in animals is applicable to man. There is, however, fairly general agreement that the blood pressure is raised, the heart rate increased and peripheral vasoconstriction produced. Insufficient work has been done on the irritant effect of nicotine and the other constituents of tobacco smoke to enable clear statements to be made. However, it is probable that suffusion of the eyes and irritation of the respiratory tract result from the ammonia, volatile acids and nicotine. Possible carcinogenic factors have been much studied, 3:4 Benzpyrene has been reported but it is impossible to state what product of the tobacco tars can produce the agreed clinical cancer.

Filters of many types have been investigated, but until agreement is reached upon the harmful factors in smoke, no statement can be made upon absolute filter values. There is considerable evidence that tobacco itself is one of the most effective filtering media and this may have considerable clinical significance. Observers of the American scene have frequently noted the greater length of the discarded cigarette end as compared with that in Britain and many other countries. This may be one factor which is accountable for the lower incidence of bronchial carcinoma in that country.

Much discussion has centred around the presence or absence of addiction in relation to nicotine and tobacco. The attitude adopted by contestants is largely determined by their definition of the term and also by their own subjective reaction. Objective analysis is difficult in these circumstances but it is certain that many people have found themselves dependent psychologically and physically. Prisoners of war suddenly deprived, have been known to fight ferociously with close and valued friends for possession of a small discarded length of cigarette. The value placed on a packet of these in Europe at the end of the war suggested something more than an easily corrected habit. The reaction of a patient, almost moribund with chronic cough, whose symptoms have been exacerbated for years by smoking, is as pathetic as any other drug addict. An excuse or reason can still be found for continuing to smoke when the respiratory system is almost overwhelmed with years of chronic damage.

Whatever term we use-habit or addiction-it is essential to realise that few heavy smokers can give up easily in a society where 60 to 70 per cent. of their fellows are only too pleased to assist in their restarting. No effective antidote to nicotine has yet been discovered. Subtle and all pervading advertisement is combined with social custom to defeat many who are anxious to rid themselves of a bondage which has severe financial as well as medical implications.

\section{Clinical Effects of Smoking Carcinoma of the Bronchus}

Statistical studies (Doll and Hill, 1950, 1952; Levin, Goldstein and Gerhardt, 1950; Mills and Porter, 1950; Schrek, Baker, Ballard and Dolgoff, 1950; Wynder and Graham, 1950; Koulumies, I953; Sadowsky, Gillian and Cornfield, I953; Wynder and Cornfield, I953; Breslow, Hoaglin, Rasmussen and Abrams, 1954; Watson and Coute, 1954) of unimpeachable quality have shown a rise in the carcinoma rate in countries where tobacco consumption has increased. This rise is proportional, in most series, to the amount smoked, especially in the case of cigarettes. The outstanding investigations of Doll and Bradford Hill in this country have set a pattern in thoroughness and expert assessment which may act as a standard throughout the world. Despite much opposition to their findings no effective scientific criticism has been offered against them. Much controversy would have been prevented if those opposing the relationship had read all the evidence set out so dispassionately by these statistical experts who began their carefully controlled investigations with a bias against a possible causative relationship. Gradually irrefutable evidence was built up which accords with clinical experience.

The extent of the problem in this country can be measured by mortality figures. These are set out in Fig. I. They show a rise in yearly mortality rate which is unparalleled in other forms of cancer. There is little doubt that a portion of this increase, especially in the late r 930 s and early 408 was due to increased accuracy of diagnosis and to more effective treatment of pneumonia which so often complicates carcinoma even in its early stage. However, when allowance is made for these factors there is still a formidable and increasing mortality to be accounted for. Fig. 3 shows the contrast between the fall in mortality from tuberculosis in England and Wales and the increase in deaths from this disease since 1940. A percentage of lung carcinoma does occur in those who have never smoked or who have smoked insignificant amounts. Most investigators find this not to exceed 15 per cent. The clinical history in the remainder follows a pattern which lends support to those investigating the problem from a statistical angle. In many patients smoking, most frequently of cigarettes, began at an early age, often 12 to 16 years and reached its maximum in a few years time-a maximum which varied from 15 to 35 


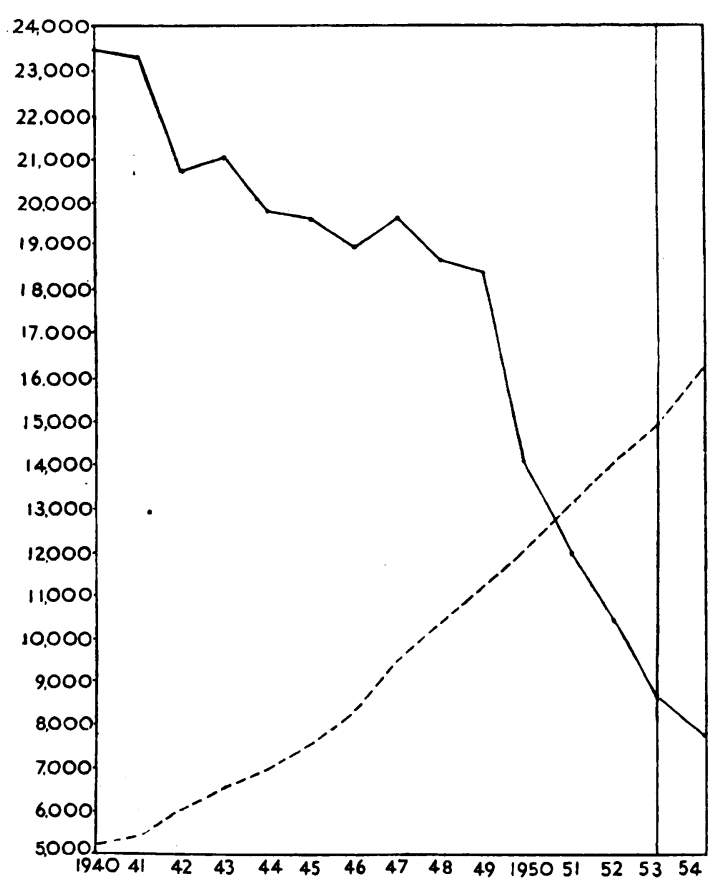

DEATHS FROM CARCINOMA OF LUNG AND PLEURA AND PULMONARY TUBERCULOSIS FROM 1940-1953

FIG. 3.- Total deaths from tuberculosis-falling curve - plotted against total deaths from cancer of lung - rising curve-in England and Wales, 1940-54.

daily at which it has been maintained for many years. Troublesome 'bronchitis' may have led to a reduction after the age of 50 to 55 but rarely has the habit been given up by the time the patient seeks advice for symptoms usually associated with advanced or complicated carcinoma of the bronchus. In 1955, most of our patients seen commenced the cigarette habit during the $1914-18$ war and their lesion is developing during the decade 55 to 65 years of age. Numbers of patients are met who have proven disease between 45 and 55 , but usually they are amongst the heaviest smokers, having 35 to 80 cigarettes daily to their credit. As Doll and Bradford Hill showed, the risk is proportionate to the amount smoked. It is impossible to speak with scientific accuracy about the number of cigarettes consumed by affected persons but except for the exceptional cases and very heavy smokers, 35 to 40 years elapses between the onset of the habit and the finding of the cancer. This clinical fact makes thoughtful physicians very anxious when relating the future of our smokers to the rise in cigarette consumption since 1914. A graph of cancer deaths projected 40 years after the rise in tobacco consumption and following the present trends gives reason for more than apprehension. The graph of cigarette consumption reached its maximum in 1945 , for once again the rigours of war were said to be alleviated by ever increasing addiction. Subsequent full employment associated with universal military training is maintaining our graph of consumption at almost the r 945 peak.

It is pathetic to realise that this aetiological factor in the case of an almost untreatable cancer has not been hailed by our profession and has not stimulated a preventive campaign which could do much to prevent hundreds of thousands of deaths in the next 30 to 40 years. A probable explanation may be in the fact that in $195 \mathrm{I}$, as shown by Doll and Bradford Hill (1954), 87.3 per cent. of male doctors smoked and more than 20 per cent. consumed more than 25 cigarettes daily. We cannot afford to wait for the detection of the precise carcinogen before taking action. The mortality from carcinoma of the bronchus dropped considerably in some European countries during the war when cigarettes became almost unobtainable. These facts suggest that abstention or marked diminution of smoking for only a few years may lead to much saving of life, but there may be other explanations for these war-time figures. Too often, at the moment, even within the profession people refuse to make the effort of abstaining from smoking with the assertion that 'my damage is done, it is too late.' There is no scientific evidence to justify this attitude. We do not know in individual cases how long smoking must continue before the inception of cancer, nor do we know whether the first or the last ten years of exposure is the more important in its evolution. Much discussion has centred around other possible carcinogens, but the evidence incriminating atmospheric pollution or the products of the internal combustion engine is meagre.

\section{Bronchitis}

Our long national smoking habits are associated with a bronchitis morbidity and mortality which is the highest in any country where statistics are kept. The irritant effect of the cigarette combines with the general atmospheric pollution of our industrialized cities and the vitiated atmosphere of factory, foundry and mine to produce a chronic and deteriorating lung condition which is made worse by each winter's virus infections. No effective remedy for such cough can be found without the full co-operation of the patients and the complete cessation of smoking. The full extent of the damage to our respiratory tract is difficult to assess but in I95 I, official statistics show that 26.6 million working days were lost by the insured population while the annual deaths remain around 30,000 and have been comparatively uninfluenced by modern therapeutic advances, Fig. 4. At 


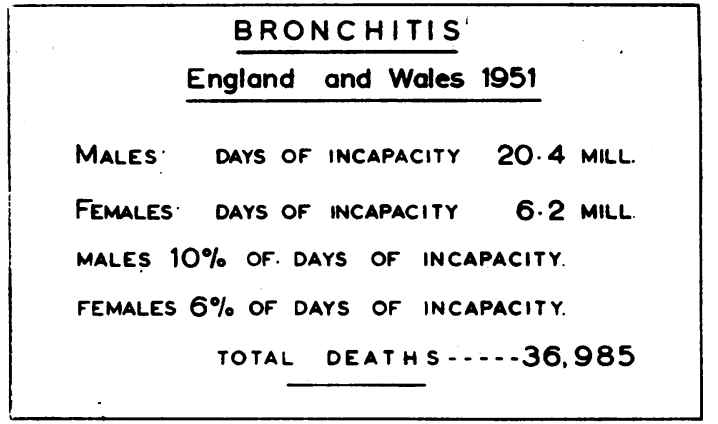

FIG. 4.-Number of working days lost in England and Wales from bronchitis in males and females, $195 \mathrm{I}$. Total deaths from same condition.

present the problem of bronchitis is more serious than cancer of the lung, but the role played by smoking is not so clear cut. In most clinical cases it must be regarded as a serious adjuvant.

\section{Cardiovascular System}

The commonest symptom produced by smoking 15 or more cigarettes each day is left thoracic discomfort and pain. This is usually experienced in the fifth left interspace, is of a dull aching character and is associated with occasional stabbing episodes which may alarm the patient. These symptoms not infrequently bring the patient to his practitioner and subsequently to a cardiologist. They are rarely found with any organic lesion but afford an opportunity for discussing the total effect of smoking on human physiology. This symptom is probably the commonest basis for anxiety in relation to the heart.

\section{Myocardial Infarction}

The evidence relating smoking to the increase of coronary atheroma and thrombosis is not conclusive although the association of heavy smoking and early onset of myocardial infarction is a feature of the investigation by Hammond et al. (1954).

Where symptoms of ischaemia have developed and the myocardium is increasingly dependent upon a collateral circulation, smoking is harmful as in peripheral vascular disease. Complete abstention should be enjoined, but where this proves very difficult, severe restriction must be insisted upon.

\section{Peripheral Arterial Disease}

Where atheroma has led to sufficient narrowing of large arteries in the limbs to give rise to ischaemic symptoms or where occlusion has actually occurred, tobacco undoubtedly maintains and exacerbates the symptoms. This effect probably results from the narrowing known to occur in the arterioles and capillaries thus diminish- ing the efficiency of the collateral circulation on which the limb is so dependent. For similar reasons it exerts a deleterious effect in established cerebrovascular disease and Raynaud's syndrome of severe degree. Thromboangitis obliterans develops from the use of tobacco by susceptible people and the disease will develop and progress as long as smoking is continued. No method of treatment, not even sympathectomy, abolishes the harmful influence. Wright (1954) quotes the effect of smoking filtered cigarettes. 'This patient first had active thromboangitis obliterans in 1940. In 194I he stopped smoking and his symptoms remained quiescent until 1949, when he started to smoke again. Within six months gangrene of three toes developed. Once more on abstinence from smoking and with other therapy the disease became quiescent and the man was free from symptoms. In the spring of 1954 , impressed by the advertising of filtered cigarettes he started to smoke them. Again his disease has been reactivated and he has early signs of pregangrenous involvement of the tips of the toes.' Fortunately this is a rare but very disabling disease and there is little doubt that tobacco is the principal aetiological factor.

\section{Gastrointestinal Tract}

Much speculation has centred around the possibility of peptic ulcer being caused bye smoking. However, such scientific investigation as has been undertaken fails to demonstrate any causative relationship. There is some evidence to suggest that effective healing of ulcers may be delayed by excessive smoking. Batterman (I955) in summing up states that 'as far as diseases of the stomach and duodenum are concerned control of the use of tobacco is essential for proper medical management of the patient.'

Many functional disturbances of the gastrointestinal tract undoubtedly result from excessive smoking while the appetite is held in abeyance by it. The mechanism through which this is mediated is not well understood but the action on gastric motility together with some increase of blood sugar may partially explain the fact. However, one clinical effect of abstention is an almost invariable increase of appetite, enjoyment of food and, unfortunately, a gain in weight.

Careful review of the effect of the habit in the nervous system would yield little of scientific value beyond the rare occurrence of tobacco amblyopia, more common in pipe smokers and probably associated with vitamin deficiency.

However, we find no evidence anywhere to suggest that any psychological benefit commensurate with the risks to life and health are obtained by the inveterate smoker. 


\section{Summary}

I. Sixty-five per cent. of men and 40 per cent. of women over 16 are regular smokers; 87.3 per cent. of male doctors over 35 years have similar habits.

2. A short review of constituents of cigarette smoke and some of its pharmacological action is given.

3. The present yearly death rate from cancer of the bronchus of 17,000 in England and Wales is shown to be due mainly to smoking, especially cigarettes.

4. This disease has caused 100,000 deaths in the past ten years and reasons are given for suggesting that we are only in the early stages of an epidemic which will result in half a million deaths in the next 20 to 30 years.

5. Preventive action by the profession and the Ministry of Health is urgent and it might be rapidly helpful.

6. The mortality and morbidity from bronchitis is greater in Britain than in any other country where statistics are available. The part played by smoking in this condition is important.

7. The effect of smoking on severe arterial disease is summarized.

8. The question is posed: Are there advantages from smoking which compensate for the known ill effects on health ? The answer must be an emphatic NO.

\section{Acknowledgments}

I am indebted to Dr. Richard Doll for the use of Fig. 4, and to the Medical World for permission to publish this.

\section{BIBLIOGRAPHY}

BATTERMAN, R. C., ' The Biologic Effects of Tobacco' (Editor: Wynder, E. L.), I955, London.

BRADFORD, J. A., HARLAN, W. R., HARLAN, E. S. and HANMER, H. R. (I937), Indust. Eng. Chem., 29, 45.

BRESLOW, L., HOAGLIN, Le M., RASMUSSEN, G. and ABRAMS, H. K. (1954), Amer. Э. Pub. Hlth., 44, 17 1.

BURN, J. H. (I95 I), Brit. med. ₹., ii, 199.

DOLL, R., and HILL, A. B. (1950), Ibid., ii, 739.

DOLL, R., and HILL, A. B. (1952), Ibid., ii, 1271 .

HAMMOND, E. C., and HORN, D. (r954), f. Amer. Med. Ass., $155,1,316$.

KOSAK, A. I., ' The Biologic Effects of Tobacco' (Editor: Wynder, E. L.), 1955, London.

KOULUMIES, M. (1953), Acta Radiol., Stockh., 39, 255.

LEVIN, M. L., GOLDSTEIN, H., and GERHARDT, P. R. (1950), F. Amer. Med. Ass., 143, 336.

MILLS, C. A., and PORTER, M. M. (1950), Cancer Res., 10, 539. SADOWSKY, D. A., GILLIAM, A. G., and CORNFIELD, J. (1953), F. Nat. Cancer Inst., 13, 1, 237.

SCHREK, R., BAKER, L. A., BALLARD, G. P., and DOLGOFF, S. (1950), Cancer Res., 10, 49.

WATSON, W. L., and CONTE, A. J. (1954), Cancer, 7, 245.

WRIGHT, I. S., 'The Biologic Effects of Tobacco' (Editor: Wynder, E. L.), I955, London.

WYNDER, E. L., and CORNFIELD, J. (1953), New Engl. F. Med., 248, 44I.

\section{CARCINOMA OF THE BRONCHUS}

\section{(Postgraduate Medical Journal)}

Price 3s. 10d. post free

\section{INTRODUCTORY}

Maurice Davidson, D.M., F.R.C.P.

THE INCIDENCE AND AETIOLOGY OF PRIMARY CARCINOMA OF THE LUNG

C. E. Drew, M.V.O., F.R.C.S.

\section{MEDICAL ASPECTS}

J. Anderson, M.D., F.R.C.P.

RADIOLOGICAL ASPECTS

G. Simon, M.D., D.M.R.E., F.F.R.

\section{UNUSUAL MANIFESTATIONS}

J. Smart, M.D., F.R.C.P.

CYTOLOGICAL EXAMINATION OF THE SPUTUM AND PLEURAL EFFUSION

J. L. Pinniger, D.M., M.R.C.P.

THE SCOPE OF RADIOTHERAPY

Gwen Hilton, D.M.R.E., F.F.R.

SURGERY OF CARCINOMA OF THE BRONCHUS

L. L. Bromley, M.Chir., F.R.C.S. 